\title{
Nurses' Health Study: demonstrating the impact of research, and adapting new measures and approaches to increase relevance and effect of cohort studies
}

\section{Graham A Colditza,b,c}

a Division of Public Health Sciences, Department of Surgery, Washington University School of Medicine, US

b Siteman Cancer Center, St Louis, Missouri, US

c Corresponding author: colditzg@wustl.edu

\section{Article history}

\section{Publication date: July 2016}

Citation: Colditz GA. Nurses' Health Study: demonstrating the impact of research, and adapting new measures and approaches to increase relevance and effect of cohort studies. Public Health Res Pract. 2016;26(3):e2631628. doi: http://dx.doi. org/10.17061/phrp2631628

\section{Key points}

- Historically, many cohorts depend on a single baseline questionnaire to assess exposures. By continuing to contact participants and update exposure measures, the Nurses' Health Study has allowed the addition of new exposures that address emerging public health issues. This has set the standard for more contemporary cohort studies

- Repeated measures allowed the study of change and time from exposure in relation to the changing risk of disease or benefits of prevention

- Documenting incident cases of many diseases, beyond the original focus on cancer, gives richer insights into women's health and wellbeing as they age, demonstrating the risks and benefits of potential prevention interventions

\section{Abstract}

The Nurses' Health Study, a cohort of 121701 female registered nurses, was established in 1976 to prospectively address the relationship between the use of oral contraceptives and the risk of breast cancer. Through followup questionnaires every 2 years, exposures have been updated and new exposure assessments added. Repeated measures have allowed a broad range of analyses, including change measures and risk according to time since exposure. Responding to emerging public health issues and accessing new measures (such as exposure to silicone implants, air pollution and the built environment) has allowed investigators to address an evolving spectrum of topics. Prospective data on a wide range of chronic conditions have allowed assessment of preventable fractions of diseases, development of risk prediction models, and other applications that bring data to bear on translation of epidemiologic findings to health policy and practice. The aim of this report is to highlight the features of the Nurses' Health Study and other cohorts that demonstrate continuing contributions to the changing epidemiology of chronic conditions.

\section{Introduction}

The Nurses' Health Study began in the US in 1976 and continues 40 years later. This paper summarises a few examples of how the cohort has adapted to changing public health issues and how it continues to contribute across a broad range of health conditions.

We have previously addressed the use of data from cohort studies such as the Nurses' Health Study to address the overall impact of the National Cancer Institute-funded research program in cancer epidemiology. ${ }^{1}$ In particular, we focused on the phases of the discovery, development and delivery paradigm of cancer research. Evidence from prospective cohort studies can help to explain the aetiology of disease with fewer sources of bias than retrospective 
studies. However, tracing research reports to their use as part of the scientific evidence base - to inform social strategies to reduce the burden of disease and improve population health - is less well developed. Using this approach, we showed that the evidence from the study has contributed to the International Agency for Research on Cancer reports on alcohol and cancer, exogenous hormones and breast cancer, and to numerous reports of the US Surgeon General. ${ }^{1}$ These outcomes may be expected of a well-conducted cohort study contributing to the establishment of causality.

The Nurses' Health Study cohort was established in 1976 to evaluate risks to women's health, including the relationships between oral contraceptives and breast cancer risk; exogenous hormone therapy and breast cancer risk; and smoking, hair dyes and cancer risk. However, the cohort has evolved to address a broad range of lifestyle factors, such as exposure to silicone implants, air pollution and the built environment. ${ }^{2}$ The addition of biological samples allowed the research to expand to study biomarkers of exposure to, for example, diet, hormones and trace elements ${ }^{2}$ (see Figure 1). The study also expanded from an original focus on cancer to include cardiovascular disease (CVD), type 2 diabetes, fractures, rheumatologic conditions and other outcomes of interest in women's health. This expansion required funders to accept a core role for the National Cancer Institute and secondary roles for other funding bodies.

\section{Responding to public health issues}

The development of the Nurses' Health Study included responding to public health issues. Additional important questions that were brought to the cohort included whether silicone breast implants increased the risk of connective tissue diseases. Dr Matthew Liang, a rheumatologist and colleague at Harvard Medical School, after attending a Food and Drug Administration hearing about implants, asked the investigators if the Nurses' Health Study might address the issue prospectively.

Figure 1. Evolution of the Nurses' Health Study

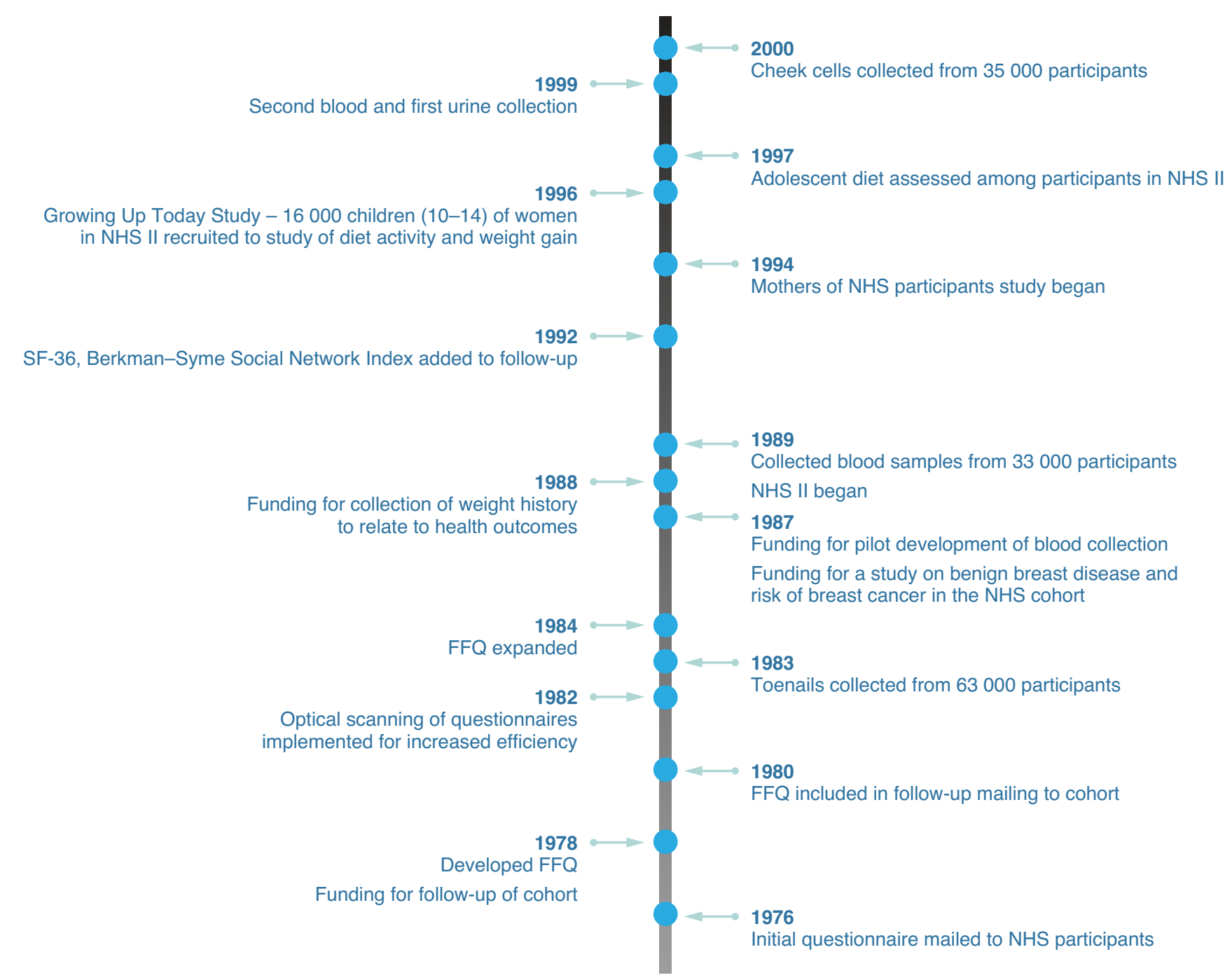


Dr Liang had already collaborated on confirmation of rheumatologic conditions within the cohort. By 1992, 109750 women were still participating in the study. Among many other topics in the 1992 biennial questionnaire, we asked participants if they had ever had breast implant surgery, or silicone, paraffin or collagen injections. Of the 89376 women (81.4\%) who returned the questionnaire, 88153 answered the questions about breast implants and injections. We sent a supplementary questionnaire to obtain details about type of implant and indications to the 1861 women who reported having breast implants, or any sort or silicone, paraffin or collagen injections. Overall, we observed no association between implants and incidence of connective tissue diseases. ${ }^{3}$

Other exposures that are not readily assessed through intervention studies and, hence, require observational designs include rotating shift work. The Nurses' Health Study represented a unique resource - a cohort of nurses who had a personal history of shift work. Participants had all been trained as registered nurses before enrolment and many continued to participate in the workforce. In 1988, we assessed the total number of years participants had worked rotating shift work. We showed a significant relationship between more years of rotating night shift work and risk of coronary heart disease (6 or more years of shift work vs never worked shift work: RR 1.51; 95\% Cl $1.12,2.03)^{4}$, increased risk of breast cancer with a trend of increasing risk with increasing years of rotating night shifts (30 or more years of shift work vs never worked shift work: RR 1.36; $\mathrm{Cl} 1.04,1.78)^{5}$, and an equal increase in the risk for colorectal cancer. ${ }^{6}$

\section{Repeated measures}

One important feature of the cohort follow-up has been the repeated assessment of exposure over time to, for example, weight fluctuations, tobacco smoke and diet. The cohort has enabled detailed assessment of the impact of weight change across the lifecourse partitioning weight change from age 18 to current age (if premenopausal) or to menopause, and then change after menopause among postmenopausal women. We showed that weight loss after menopause was associated with a reduction in the risk of breast cancer. There was also a clear relationship between smoking cessation (and remaining a nonsmoker) and change in total mortality by time since quitting ${ }^{7}$, and data are not confounded by smoking recidivism (a factor that substantially underestimates the benefits of quitting in cohorts that do not update exposure status for smoking during follow-up). Changes in dietary patterns and nutrients over time allowed us to evaluate the changes in risk of CVD compared with those who did not change their diet quality. Compared with women who did not increase the quality of their diet, those who had the largest improvements in diet quality over 4 years had
7-9\% lower risk of CVD during the subsequent 4 years, and those whose diet quality worsened had a significantly increased risk of CVD. ${ }^{8}$ Diet validation data comparing food frequency questionnaires with diet records also allowed for development of methods to adjust for measurement error.

Studies also distinguish time-course relationships between dietary exposures and outcomes, perhaps most fruitfully for colorectal cancer. By addressing the time from diet assessment of folate intake and risk of colorectal cancer, Lee et al. ${ }^{9}$ showed that a reduction in colorectal cancer was most evident 12-16 years after diet assessment, and that protection was reduced the shorter the follow-up from diet assessment. This confirmed that folate is operating earlier rather than later in the development of colorectal carcinogenesis.

\section{Risk models}

In the 1980s, using the data from the Nurses' Health Study cohort, I was challenged by Dr Chris Bain to take the Pike model of breast cancer incidence ${ }^{10}-$ which states that breast tissue ageing begins at menarche, decreases after first birth and decreases further after menopause, and allows for an adverse effect of first pregnancy - and attempt to validate this model in the prospective cohort. We developed a lifecourse model of incidence, with risk accumulating at different rates corresponding to intervals defined by reproductive variables, menarche, age and spacing of births, and menopause, and according to weight and height across life. The 20 years of research has provided insights to the aetiology of breast cancer, allowed for the refined analysis of the interval from menarche to first full-term pregnancy (documenting the previous reports from casecontrol studies that closer spacing of births, and not just the total number of pregnancies, lowers the risk) and helped to expand the field of risk prediction in cancer. ${ }^{11}$ We noted that risk of benign breast disease accumulated particularly before menarche ${ }^{12}$, although we have not yet determined what lifestyle or environmental exposures are responsible for, or modify, this risk pathway to breast cancer. Expanding from the work of Armitage and Doll ${ }^{13}$, we also applied a lifecourse approach through logincidence modelling to ovarian cancer, melanoma and colorectal cancer risk prediction.

\section{Expanding the scope}

In this section, I demonstrate the changing face of epidemiologic research during the past 40 years, and the adaptability required by researchers and funders to continue to address timely public health issues. Among the early changes in the conduct of epidemiological studies - and often followed by others - is the use of pathology samples to refine the understanding of disease aetiology. ${ }^{14}$ This first applied to benign breast lesions, but 
after collection of tissue blocks from incident cases of invasive breast cancer and colon cancer, we applied a range of biomarker studies to better understand pathways and mechanisms from lifestyle to cancer aetiology and outcomes. ${ }^{15,16}$ This latter evaluation showed that a history of breastfeeding was inversely related to basal-like breast cancer. ${ }^{16}$ The cohort has also been a rich source of evidence on adiposity in childhood and its relationship to subsequent risk of breast cancer, where it is inversely related to oestrogen receptor-negative breast cancer. ${ }^{17}$

Studies of survivorship after cancer diagnosis and treatment were also an early addition to the ongoing cohort study. In part, this reflected the growing number of survivors in the population and a search for guidance on lifestyle after cancer. In 1992, we added measures of quality of life to the cohort follow-up questionnaire and then followed participants with repeated measures every 4 years, enabling the quantification of change in quality of life after diagnosis of breast cancer, with the potential to control for prediagnostic values. ${ }^{18}$ Subsequent studies addressed physical activity and diet changes after cancer diagnosis, showing that higher levels of physical activity reduced risk of recurrence and death among women with breast and colorectal cancer. ${ }^{19}$

Study participants live across the US, and this afforded opportunities to study the relationship between air pollution and health outcomes, while controlling for established causes such as smoking and blood pressure when assessing the incidence of CVD. ${ }^{20}$ In addition, we added measures of neighbourhood walkability to the underlying cohort data on individually assessed lifestyle measures. With these data, investigators have also assessed exposure to particulate air pollution, and the relationship between built environment, physical activity and body mass index. Air pollution and incidence of a broad range of chronic conditions were studied once the residential history and air quality data were linked and updated.

Another broad application of the cohort has been to determine the preventable burden of disease across multiple outcomes, from heart disease to diabetes and cancers. This again reflects both the power of the cohort and the richness achieved through detailed investigation of aetiology of many chronic conditions in women across middle and older ages. The wealth of data attest to the exogenous factors driving incidence of these chronic conditions in Western society. ${ }^{21}$

\section{Conclusion}

The evolving focus on current issues of public health importance means investigators need to refine exposure measures that can be added to the cohort follow-up, particularly when repeated questionnaire assessments are a routine part of the cohort. Further, linking individual cohort member data to more grouplevel measures - such as features of urban design and air pollution - that are now more readily available to investigators allows for timely focus on multilevel drivers of public health outcomes. The breadth of health conditions being documented and studied all add to the value of the Nurses' Health Study as a model of a cohort study impacting public health policy and practice. Some findings translate to changes in regulation, such as transfat and its effect on heart disease and diabetes; others support prevention guidelines, such as aspirin and reduction in risk of colorectal cancer; and others guide recommendations by the US Surgeon General, such as on the adverse health effects of smoking.

\section{Competing interests}

None declared

\section{References}

1. Colditz GA, Winn DM. Criteria for the evaluation of large cohort studies: an application to the nurses' health study. J Natl Cancer Inst. 2008;100(13):918-25.

2. Colditz GA, Hankinson SE. The Nurses' Health Study: lifestyle and health among women. Nat Rev Cancer. 2005;5(5):388-96.

3. Sanchez-Guerrero J, Colditz GA, Karlson EW, Hunter DJ, Speizer FE, Liang $\mathrm{MH}$. Silicone breast implants and the risk of connective-tissue diseases and symptoms. N Engl J Med. 1995;332(25):1666-70.

4. Kawachi I, Colditz GA, Stampfer MJ, Willett WC, Manson JE, Speizer FE, Hennekens CH. Prospective study of shift work and risk of coronary heart disease in women. Circulation. 1995;92(11):3178-82.

5. Schernhammer ES, Laden F, Speizer FE, Willett WC, Hunter DJ, Kawachi I, Colditz GA. Rotating night shifts and risk of breast cancer in women participating in the nurses' health study. J Natl Cancer Inst. 2001;93(20):1563-8.

6. Schernhammer ES, Laden F, Speizer FE, Willett WC, Hunter DJ, Kawachi I, et al. Night-shift work and risk of colorectal cancer in the nurses' health study. J Natl Cancer Inst. 2003;95(11):825-8.

7. Kenfield SA, Stampfer MJ, Rosner BA, Colditz GA Smoking and smoking cessation in relation to mortality in women. JAMA. 2008;299(17):2037-47.

8. Sotos-Prieto M, Bhupathiraju SN, Mattei J, Fung TT, Li $\mathrm{Y}$, Pan A, et al. Changes in diet quality scores and risk of cardiovascular disease among US men and women. Circulation. 2015;132(23):2212-9.

9. Lee JE, Willett WC, Fuchs CS, Smith-Warner SA, Wu K, $\mathrm{Ma} J$, Giovannucci E. Folate intake and risk of colorectal cancer and adenoma: modification by time. Am J Clin Nutr. 2011;93(4):817-25. 
10. Pike MC, Krailo MD, Henderson BE, Casagrande JT, Hoel DG. 'Hormonal' risk factors, 'breast tissue age' and the age-incidence of breast cancer. Nature. 1983;303(5920):767-70.

11. Colditz G, Wei EK. Risk prediction models: applications in cancer prevention. Curr Epidemiol Rep. 2015;2:245-50.

12. Colditz G, Rosner B. Cumulative risk of breast cancer to age 70 years according to risk factor status: data from the Nurses' Health Study. Am J Epidemiol. 2000;152(10):950-64.

13. Armitage $P$, Doll R. The age distribution of cancer and a multistage theory of carcinogenesis. $\mathrm{Br} \mathrm{J}$ Cancer. 1954;8:1-12.

14. London SJ, Connolly JL, Schnitt SJ, Colditz GA. A prospective study of benign breast disease and the risk of breast cancer. JAMA. 1992;267(7):941-4.

15. Tamimi RM, Colditz GA, Wang Y, Collins LC, Hu R, Rosner B, et al. Expression of IGF1R in normal breast tissue and subsequent risk of breast cancer. Breast Cancer Res Treat. 2011;128(1):243-50.

16. Tamimi RM, Colditz GA, Hazra A, Baer HJ, Hankinson SE, Rosner B, et al. Traditional breast cancer risk factors in relation to molecular subtypes of breast cancer. Breast Cancer Res Treat. 2012;131(1):159-67.
17. Baer HJ, Tworoger SS, Hankinson SE, Willett WC. Body fatness at young ages and risk of breast cancer throughout life. Am J Epidemiol. 2010;171(11):1183-94.

18. Michael YL, Kawachi I, Berkman LF, Holmes MD, Colditz GA. The persistent impact of breast carcinoma on functional health status: prospective evidence from the Nurses' Health Study. Cancer. 2000;89(11):2176-86.

19. Holmes MD, Chen WY, Feskanich D, Kroenke CH, Colditz GA. Physical activity and survival after breast cancer diagnosis. JAMA. 2005;293(20):2479-86.

20. Hart JE, Puett RC, Rexrode KM, Albert CM, Laden F. Effect modification of long-term air pollution exposures and the risk of incident cardiovascular disease in US women. J Am Heart Assoc. 2015;4(12).

21. Hu FB, Manson JE, Stampfer MJ, Colditz G, Liu S, Solomon CG, Willett WC. Diet, lifestyle, and the risk of type 2 diabetes mellitus in women. $\mathrm{N}$ Engl $\mathrm{J}$ Med 2001;345(11):790-7.

\section{Copyright: (c) (i) (2)}

(C) 2016 Colditz. This article is licensed under the Creative Commons Attribution-NonCommercial-ShareAlike 4.0 International Licence, which allows others to redistribute, adapt and share this work non-commercially provided they attribute the work and any adapted version of it is distributed under the same Creative Commons licence terms. See: www.creativecommons.org/licenses/by-nc-sa/4.0/ 